\title{
There's no fun like work
}

\author{
Carl L. Backer, MD
}

\footnotetext{
From the Division of Cardiovascular-Thoracic Surgery, Ann \& Robert H. Lurie Children's Hospital of Chicago, and Northwestern University Feinberg School of Medicine, Chicago, Ill.

Disclosures: Dr Backer is a consultant for W.L. Gore \& Associates, Flagstaff, Ariz.

Received for publication May 15, 2017; accepted for publication May 22, 2017; available ahead of print June 24, 2017.

Address for reprints: Carl L. Backer, MD, Division of Cardiovascular-Thoracic Surgery, Ann \& Robert H. Lurie Children's Hospital of Chicago, 225 E Chicago Ave, mc 22, Chicago, IL 60611 (E-mail: cbacker@ luriechildrens.org).

J Thorac Cardiovasc Surg 2017;154:1339

$0022-5223 / \$ 36.00$

Copyright (c) 2017 by The American Association for Thoracic Surgery

http://dx.doi.org/10.1016/j.jtcvs.2017.05.083
}

Dearani and colleagues from the Mayo Clinic $^{1}$ draw our attention to some of the finer points of the educational processes of surgeons. There is much to be learned from this elegant analysis; it is rare and refreshing in the current era to read an article co-authored by cardiac surgeons, urologists, radiologists, and psychologists. As a former Mayo medical student myself (full disclosure), I speculate that the origin of this analysis may lie in a famous quote from William J. Mayo: "There's no fun like work!" Wellperformed surgical procedures (work) with great benefit to the patient is very rewarding (fun). The authors emphasize 4 components of surgical training: deliberate practice, structure, improvisation, and the relatively new component of advanced imaging.

The authors are absolutely correct that advances in anatomic imaging help facilitate the planning and performance of surgical procedures. At our institution, pediatric cardiac radiologists join us for rounds every morning to review the anatomic details of the advanced imaging studies that we now consider a standard step in preoperative planning. Moreover, we now rarely go to the catheterization lab to look at the images of a patient we are operating on the next day. We now go to the computed tomography/magnetic resonance imaging station to view comprehensive 3-dimensional images. This can be enhanced even more by 3-dimensional printing, which is rapidly becoming widely available. The days when a congenital heart surgeon opened up a heart and then decided what operation to do have essentially disappeared.

The other very interesting consideration in this review is the yin and yang between deliberate practice and improvisation. Much of this is based on Dearani's unique perspective, which is the result of having both a career as a cardiac surgeon and mastery of the jazz saxophone. Cardiac surgery is mostly deliberate practice and structure, whereas jazz is mostly spontaneous improvisation. These seemingly perfection."1

\section{Reference} 1329-36.

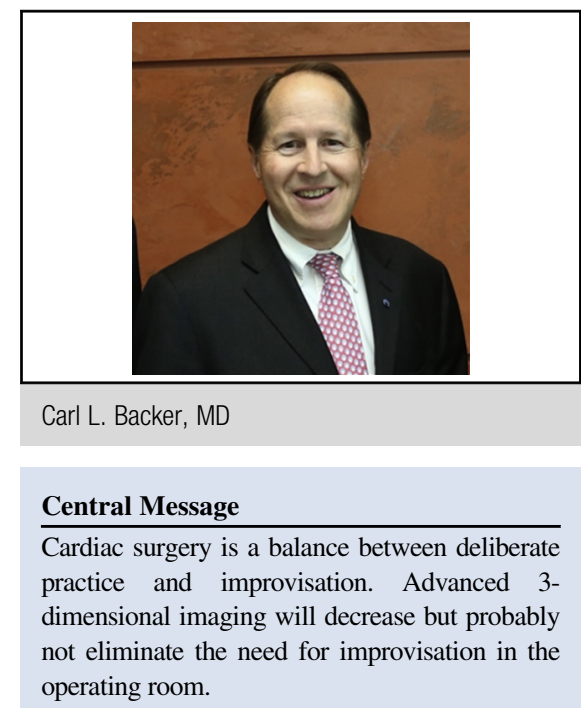

See Article page 1329.

opposite or contrary forces are actually complementary and interconnected. Deliberate practice cannot prepare one for all situations. Even after 30 years in the field of congenital heart surgery, I find myself dealing occasionally with something entirely new. That is where improvisation may suddenly be needed. Of course, deliberate practice and lots of it helps make great thoracic surgeons. The 10,000-hour rule does seem to match up with the time spent in operating rooms during cardiothoracic surgical residency. By my calculations, if a resident physician operates 6 hours a day, 5 days a week, it would take 7 years to achieve 10,000 hours. This is time well spent. However, in performance it is the ability to improvise in the setting of unexpected or previously unseen situations that separates the virtuoso performer from the rest. Three-dimensional images will decrease (but probably not eliminate) the need for improvisation in operating rooms. This analysis of how art meets science when we educate and train will help us to achieve the authors' stated goal of "surgical

1. Dearani JA, Gold M, Leibovich BC, Ericsson KA, Khabbaz KR, Foley TA, et al. The role of imaging, deliberate practice, structure, and improvisation in approaching surgical perfection. J Thorac Cardiovasc Surg. 2017;154: 